\title{
CNTNAP1 mutations cause CNS hypomyelination and neuropathy with or without arthrogryposis \\ OPEN
}

Holger Hengel, MD*

Alex Magee, MD*

Muhammad Mahanjah,

MD*

Jean-Michel Vallat, MD

Robert Ouvrier, MD

Mohammad Abu-Rashid, MD

Jamal Mahamid, MD

Rebecca Schüle, MD

Martin Schulze, PhD

Ingeborg Krägeloh-Mann, MD

Peter Bauer, MD

Stephan Züchner, MD

Rajech Sharkia, PhD

Ludger Schöls, MD

Correspondence to Dr. Schöls: Ludger.Schoels@uni-tuebingen. de

\section{ABSTRACT}

Objective: To explore the phenotypic spectrum and pathophysiology of human disease deriving from mutations in the CNTNAP1 gene.

Methods: In a field study on consanguineous Palestinian families, we identified 3 patients carrying homozygous mutations in the CNTNAP1 gene using whole-exome sequencing. An unrelated Irish family was detected by screening the GENESIS database for further CNTNAP1 mutations. Neurophysiology, MRI, and nerve biopsy including electron microscopy were performed for deep phenotyping.

Results: We identified 3 novel CNTNAP1 mutations in 5 patients from 2 families: c.2015G>A:p. (Trp672*) in a homozygous state in family 1 and c.2011C>T:p.(GIn671*) in a compound heterozygous state with c.2290C>T:p.(Arg764Cys) in family 2. Affected patients suffered from a severe CNS disorder with hypomyelinating leukodystrophy and peripheral neuropathy of sensory-motor type. Arthrogryposis was present in 2 patients but absent in 3 patients. Brain MRI demonstrated severe hypomyelination and secondary cerebral and cerebellar atrophy as well as a mega cisterna magna and corpus callosum hypoplasia. Nerve biopsy revealed very distinct features with lack of transverse bands at the paranodes and widened paranodal junctional gaps.

Conclusions: CNTNAP1 mutations have recently been linked to patients with arthrogryposis multiplex congenita. However, we show that arthrogryposis is not an obligate feature. CNTNAP1-related disorders are foremost severe hypomyelinating disorders of the CNS and the peripheral nervous system. The pathology is partly explained by the involvement of CNTNAP1 in the proper formation and preservation of paranodal junctions and partly by the assumed role of CNTNAP1 as a key regulator in the development of the cerebral cortex. Neurol Genet 2017;3:e144; doi: 10.1212/NXG.0000000000000144

\section{GLOSSARY}

AMC = arthrogryposis multiplex congenita; CASPR = contactin-associated protein; ExAC = Exome Aggregation Consortium; GERP = Genomic Evolutionary Rate Profiling; PNS = peripheral nervous system.

Recently, mutations in CNTNAP1 have been linked to patients with arthrogryposis multiplex congenita (AMC). ${ }^{1}$ Four families were described with 3 different homozygous frameshift mutations. All patients suffered from distal joint contractures and died within the first 2 months of life. Etiologically, AMC can be divided into (1) the primary manifestation of an orthopedic disorder or (2) neurologic disorders causing secondary AMC. The second group is the most

\footnotetext{
*These authors contributed equally to the manuscript.

From the Department of Neurology and Hertie-Institute for Clinical Brain Research (H.H., R. Schüle, L.S.), University of Tübingen, Germany; German Center of Neurodegenerative Diseases (DZNE) (H.H., R.S., L.S.), Tübingen, Germany; Northern Ireland Regional Genetics Service (A. M.), Belfast City Hospital, Belfast; Department of Neurology (J.-M.V.), National Reference Center for Rare Peripheral Neuropathies, University Hospital, Limoges, France; Institute for Neuroscience and Muscle Research (R.O.), The Children's Hospital at Westmead, Sydney, New South Wales, Australia; The Triangle Regional Research and Development Center (R. Sharkia), Kfar Qari' Israel; Beit-Berl Academic College (R. Sharkia), Israel; Child Neurology and Development Center (M.M.), Hillel-Yaffe Medical Center, Hadera, Israel; Rappaport Faculty of Medicine (M.M.), Technion, Haifa, Israel; Institute of Medical Genetics and Applied Genomics (M.S.), University of Tübingen, Germany; Department of Pediatric Neurology (I.K.-M.), University Medical Center Tübingen, Germany; Hussman Institute for Human Genomics (S.Z.), University of Miami Miller School of Medicine, FL; Clalit Health Services (M.A.-R.), Haifa, Israel; and Meuhedet Health Services (J.M.), North District, Israel.

Funding information and disclosures are provided at the end of the article. Go to Neurology.org/ng for full disclosure forms. The Article Processing Charge was paid by the authors.

This is an open access article distributed under the terms of the Creative Commons Attribution-NonCommercial-NoDerivatives License 4.0 (CC BY-NC-ND), which permits downloading and sharing the work provided it is properly cited. The work cannot be changed in any way or used commercially without permission from the journal.
} 
common cause of severe manifestations and is considered to be a result of fetal hypokinesia due to the underlying neurologic disease. ${ }^{2}$ Thus, AMC can be caused by different genes impairing skeletal muscles, encoding components of the neuromuscular junction or affecting axoglial development. ${ }^{1,2}$

CNTNAP1 encodes the contactin-associated protein (CASPR), a cell adhesion protein involved in the proper formation of paranodal junctions in myelinated axons. ${ }^{3-5}$ CASPR knockout mice exhibit generalized motor paresis and cerebellar signs. ${ }^{5} \mathrm{~A}$ similar phenotype is present in the shambling mouse, caused by a frameshift mutation in CNTNAP1. ${ }^{6}$ Both mutant mice exhibit abnormal paranodal junctions both in the peripheral nervous system (PNS) and in the CNS.,6 Comparable findings with abnormal paranodal junctions and abnormal myelination have been revealed by transmission electron microscopy of the sciatic nerve in CNTNAP1 patients. ${ }^{1}$ This suggests that AMC due to CNTNAP1 mutations is caused by axoglial defects.

Here, we report 5 patients with CNTNAPI mutations expanding the CNTNAP1-related phenotypic spectrum to a severe CNS disorder with hypomyelinating leukodystrophy and peripheral neuropathy, with or without arthrogryposis.

METHODS Standard protocol approvals, registrations, and patient consents. Patients were enrolled in Israel (family 1) and Northern Ireland (family 2). Written informed consent was obtained from the parents for diagnostic procedures and nextgeneration sequencing as well as for the publication of this case report including the accompanying images. The study was approved by the local ethical review board (vote 180/2010BO1).

Exome sequencing and analysis. Patients were screened for exonic variants using a whole-exome enrichment approach (SureSelectXT Human All Exon V5; Agilent, Santa Clara CA). Sequencing was performed on a HiSeq2500 (200 cycle chemistry) or NextSeq500 (300 cycle chemistry) platform (Illumina, San Diego, CA) in paired-end mode according to the manufacturers' protocol. FASTQ files were imported into GENESIS (http://thegenesisprojectfoundation.org/ $)^{7}$ for further analysis using a pipeline build on BWA, ${ }^{8}$ Picard, and FreeBayes. Variants were filtered for changes that segregated in an autosomal recessive fashion and met the "strict" criteria, which requires that variants are rare (NHLBI ESP6500 minor allele frequency $<0.1)$, present in less than 3 families within GENESIS ( 4,300 exomes), conserved (Genomic Evolutionary Rate Profiling [GERP] score $>2$ or PhastCons score $>0.6$ ), and have sufficient quality scores (Genotype Quality $>75$ ). Sanger sequencing was performed using standard methods and chemicals. Primer sequences are available on request.
Screening for CNTNAP1 patients using GEM.app/Genesis. Previous studies on CNTNAP1-associated disease have exclusively focused on cohorts with AMC. To capture the full phenotypic spectrum caused by CNTNAP1 in an unbiased approach, we screened a total of 2,599 families with various neurologic phenotypes and a family history compatible with autosomal recessive inheritance available in the GEM.app/Genesis database at the time ${ }^{7}$ for rare homozygous or compound heterozygous CNTNAP1 mutations. Phenotypes included 492 families with neuromuscular phenotypes, 251 HSP families, 721 ALS families, and 168 families with hereditary ataxia.

Electron microscopy. As described elsewhere, ${ }^{9}$ samples of sciatic nerves were fixed for 3 hours in $2.5 \%$ glutaraldehyde in Sorensen buffer and osmificated for 1 hour in $1 \%$ OsO4. Afterward, they were rinsed in Sorensen buffer, dehydrated in graded acetone, and embedded in Epon. Semithin sections $(1 \mu \mathrm{m})$ were stained with toluidine blue. Ultrathin sections were stained with uranyl acetate and lead citrate. The sections were observed through a JEOL electron microscope.

RESULTS Identification of new CNTNAP1 mutations. In a large Israeli consanguineous family of Palestinian ancestry (family 1 branch A + B), we identified 2 children (figure 1) with multiple congenital anomalies affecting the skeleton and brain as indicated by fetal sonography. Polyhydramnios occurred during both pregnancies, and children were born at 34- and 35week gestation, respectively, with normal birth weight. Both children were diagnosed with AMC at birth, with clenched hands, contractures of the elbows, knees, and feet. They were noted to have microcephaly, hypotonia, absent swallow, facial diplegia, low-set ears, cleft palate, and micrognathia.

Because of profound hypoventilation, both infants required ventilatory support. Both had severe developmental disabilities and never learned to sit, walk, or talk. Later, both developed generalized epilepsy with tonic-clonic seizures.

On neurologic examination at age 9 and 12 years, severe intellectual disability of both children was noted. They had small unresponsive pupils, were unable to make eye contact, did not follow visual stimuli, and did not react to sound stimuli. Both had pronounced contractures of hands, elbows, knees, and feet and showed increased muscle tone of the extremities while the tone of axial muscles was decreased. Reflexes were increased with positive Babinski sign. Both were microcephalic and showed dysmorphic features, including micrognathia, cleft palate, and large, low-set ears (figure 2). Both received nutrition by gastrostomy and underwent tracheostomy.

Metabolic screening including amino acids, very long chain fatty acids, lactate and ammonia in serum, and organic acids in urine was normal as were CSF findings. Genetic testing excluded SMN1 mutations. Brain MRI of patient 1 , taken at the age of 5 years, showed severe hypomyelinating leukodystrophy. 


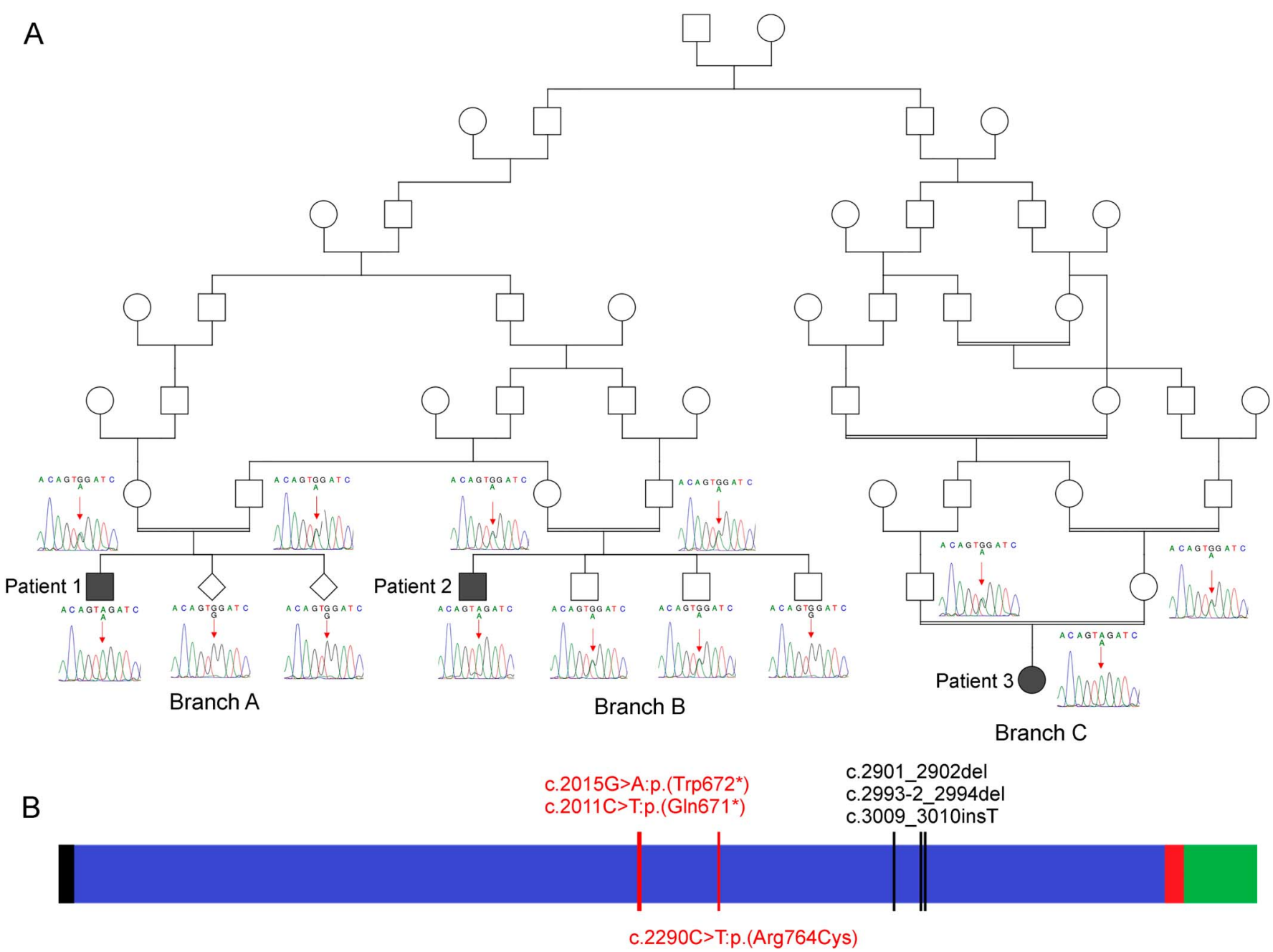

(A) Pedigree of family 1 branches A-C with multiple consanguineous loops and segregation of the CNTNAP1 variant. The identified variant (position indicated by red arrow) segregated with the disease in all affected patients. (B) Schematic representation of known and new mutations in CNTNAP1: previously described mutations are depicted in black, and new disease-causing mutations are indicated in red. The missense variant p.(Arg764Cys) has been found in a compound heterozygous state together with p.(Gln671*). All other variants were homozygous in affected patients. Blue: extracellular domain; red: helical domain (transmembrane); green: cytoplasmic domain (intracellular) (information of domains from uniprot.org).

There were no signs of myelination even in parts of the brain normally myelinated early after birth such as the posterior limb of the inner capsule. Reduced cerebral, cerebellar, and pontine volume was obvious with pronounced lack of white matter. Furthermore, a thin corpus callosum and mega cisterna magna were noted (figure 3). To determine the genetic basis, we performed whole-exome sequencing on both patients. Following the hypothesis that both patients suffer from the same genetic disorder, only overlapping variants from both exomes were considered and filtered using the strict criteria mentioned in the methods. This resulted in only 9 rare homozygous variants including only 1 truncating variant: a homozygous stop-gain mutation in exon 13 of CNTNAP1: NM_003632.2:c.2015G>A:p.(Trp672*). Sanger sequencing of all family members showed full segregation with the disease (figure 1). The parents were heterozygous for the mutation, and the healthy siblings were either heterozygous or homozygous for the wildtype. The mutation was not found in the ESP6500, 1000 Genomes, or the Exome Aggregation Consortium (ExAC) database.

Further follow-up of the family revealed a 4-weekold child in a distantly related family branch (branch $\mathrm{C}$ in figure 1A) who was born at term with a history of polyhydramnios, had similar dysmorphic features with low-set ears, micrognathia, and microcephaly and required controlled ventilation. However, there were no joint contractures or signs of AMC. Genetic testing revealed the identical homozygous CNTNAP1 mutation c.2015G >A:p.(Trp672*).

Screening for CNTNAP1 mutations reveals further nonAMC cases. An unbiased screening approach using the GEM.app/Genesis database led to the identification 

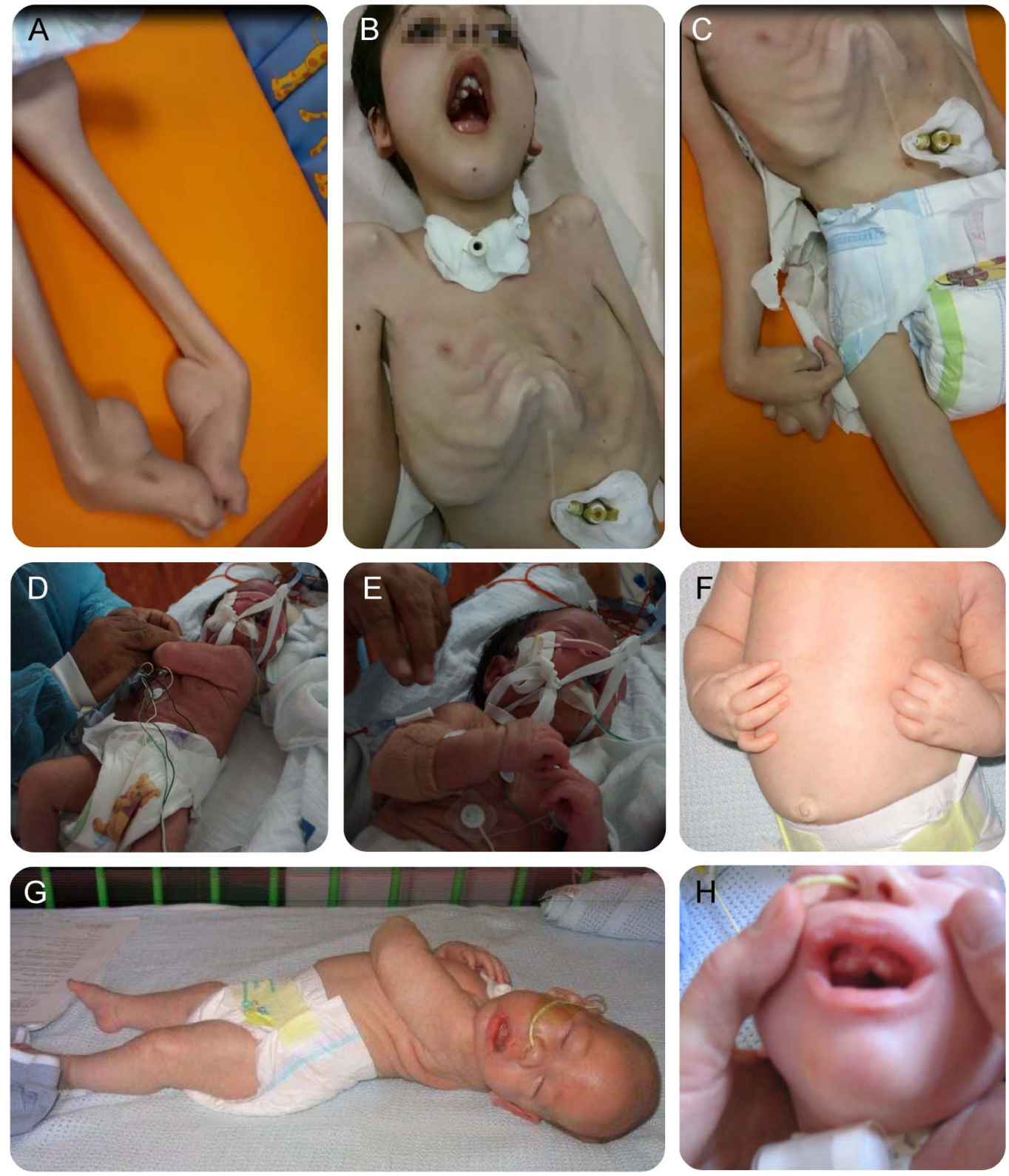

(A-C) Patient 1 with arthrogryposis multiplex congenita (AMC). (A) Contractures of the feet, (B) features including microcephaly, micrognathia, low-set ears, and cachexia, and (C) contractures of the hand and fingers. (D, E) Patient 3 without AMC but with microcephaly, low-set ears, and hypotonia. (F-H) Patient 4 without AMC. (F) No signs of contractures of the fingers, (G) hypotonia, and (H) midline notch upper gum.

of a nonconsanguineous Northern Irish family (family 2) with 2 affected brothers (patients 4 and 5 , table), who shared compound heterozygous mutations in CNTNAP1: 1 stop-gain and 1 missense mutation (NM_003632.2:c.2011C>T:p.(Gln671*) and c.2290C $>$ T:p.(Arg764Cys)). The latter changes a highly conserved polar amino acid residue (arginine) to a nonpolar residue (cysteine) (GERP score: 5.84, PhastCons: 1). Different prediction programs (Scale Invariant Feature Transform: 0.03, MutationTaster: 0.999, and PolyPhen: 0.998) $)^{10-12}$ estimate the variant to be pathogenic, and it has never been described in public databases (ExAC, ESP6500, and 1000 Genomes).

Clinical findings were similar as in family 1. Patient 4 was diagnosed with polyhydramnios and reduced fetal movements at 27 -week gestation. At birth, he was profoundly hypotonic and required ventilatory support. He was noted to have absent swallow, facial diplegia, complete ptosis, dolichocephaly, epicanthic folds, thickened nares, thickened lips, narrow ridged palate, thickened gums with a notch in the upper midline, micrognathia, and partial bilateral 2-3 toe syndactyly. He was areflexic and preferred to lie in 

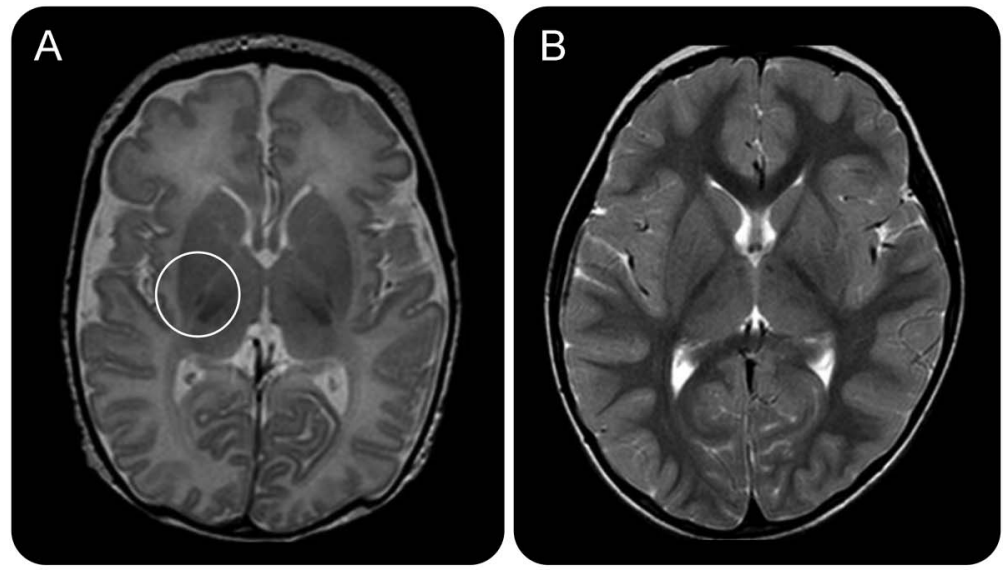
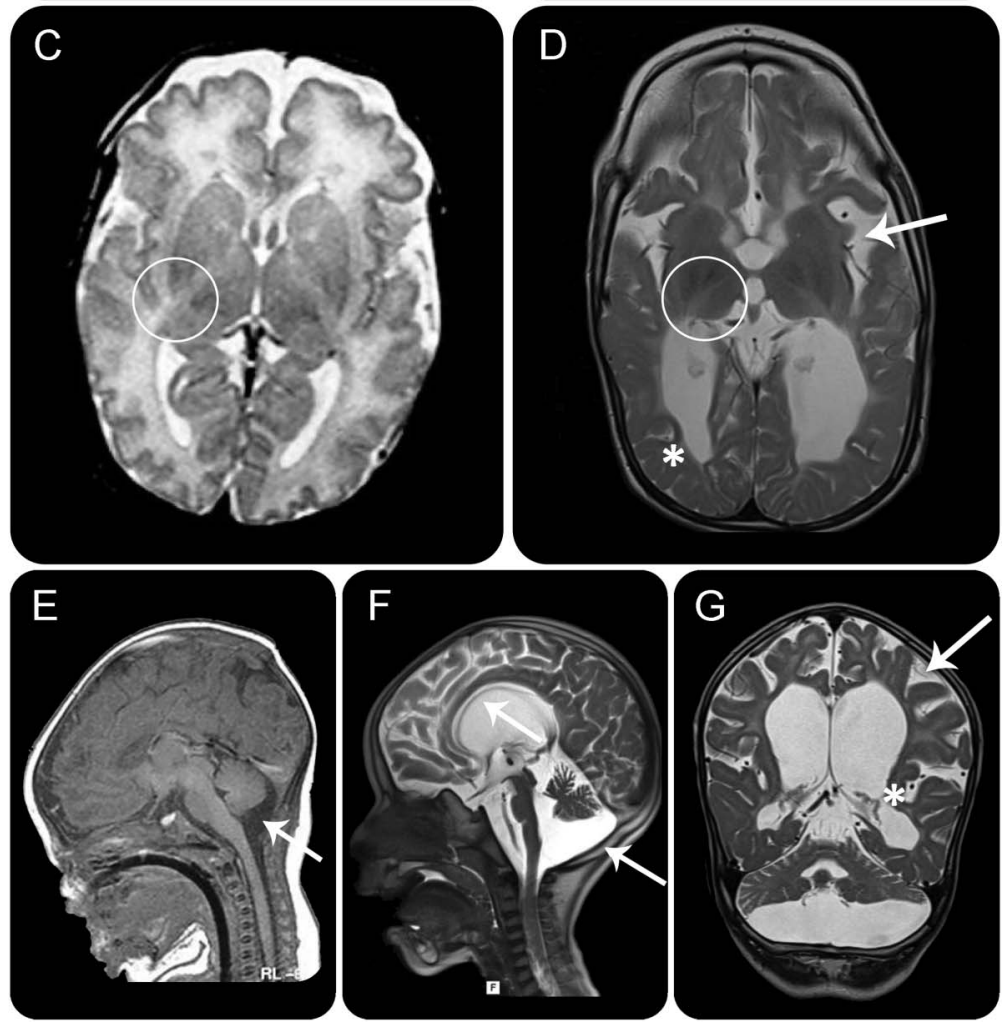

(A) T2-weighted image of healthy 8-day-old child. Signs of beginning myelination within the posterior limb of the inner capsule (PLIC; hypointense signal within the white circle). (B) T2weighted image of healthy 36 -month-old child. Myelination is complete, resulting in hypointense signals of white matter, inner capsule, and corpus callosum. (C) T2-weighted image of patient 4 taken at 4 days of age. No signs of myelination in the PLIC (white circle). No signs of obvious cortex malformation. (E) Sagittal T1 image of patient 4 at 4 days of age indicates normal cerebral, cerebellar, and pontine volume. Small mega cisterna magna is depicted by a white arrow. (D, F, G) T2-weighted images of patient 1 at 5 years of age. (D, G) White matter is hyperintense without signs of myelination; even early myelinating structures are hyperintense without myelin deposits (circle). Cerebral atrophy (white arrow) with pronounced lack of white matter (white star). (F) Midsagittal images show thin corpus callosum (white arrow), mega cisterna magna (white arrow), reduced pontine volume, and cerebellar atrophy.

a hyperextended position. Some voluntary limb movements were observed. No arthrogryposis was noted. A full range of passive limb and joint movements was possible. He was able to open his eyes for up to 40 seconds, but this gradually decreased. Tracheostomy was performed at the age of 3 weeks; with this, he was able to breathe unaided. Brainstem evoked responses confirmed bilateral sensorineural hearing loss. At the age of 10 weeks, he developed generalized clonic, brief tonic, and myoclonic seizures. Resting posture was noted to be less hyperextended, elbows and fingers were held flexed, but the range of passive movements remained full. Palliative care was introduced and he died at age 4 months. On brain MRI at the age of 4 days, any signs of beginning myelination were missing (figure 3). There were mega cisterna magna and thin corpus callosum, but clear cerebral hypoplasia or cortical malformations were not detected. Nerve conduction studies and EMG suggested sensory-motor neuropathy and denervation.

Patient 5 was the brother of patient 4. Polyhydramnios and reduced fetal movements were diagnosed at 31-week gestation. At birth, he was profoundly hypotonic with no respiratory effort. He did not swallow and muscle reflexes were absent. No invasive treatment was initiated and he died at 4 hours of age.

Sural nerve biopsy reveals paranodal abnormalities. Sural nerve biopsy of patient 4 revealed a significant axonal loss which was homogeneous between nerve fascicles. There was a significant decrease of large myelinated fibers and a great number of myelinated fibers with too thin myelin sheaths (figure 4); myelin debris was found in the cytoplasm of some Schwann cells and in a few macrophages in the endoneurial space. Electron microscopic examination of longitudinal sections showed frequent and marked widenings of the nodes of Ranvier typical of a demyelinating neuropathy. Most of the paranodal regions were characterized by loss of attachment sites of the loops, which seemed to be induced by Schwann cell processes penetrating between the axon and the loops (figure 4). Moreover, the typical transverse bands $\mathrm{s}^{13}$ that cross the paranodal junctional gap were absent.

DISCUSSION We found 3 new CNTNAP1 mutations causing a severe hypomyelinating CNS disorder and peripheral neuropathy in 2 independent families. The 2 new stop-gain mutations c.2011C>T:p. $($ Gln671*) and c.2015G>A:p.(Trp672*) occur earlier than the 2 previously described frameshift mutations with premature stop codon (c.2901_2902del and c.2994-2_2994del) and the frameshift mutation c.3009_3010ins T, thus either resulting in a severely truncated protein or nonsense-mediated decay (figure 1). The missense mutation in family 2 changes a highly conserved amino acid residue from a polar to a nonpolar residue. Taken together with huge overlap in clinical findings of all children, we have no doubt about the pathogenicity of the missense mutation. 
Table Clinical features of new cases and previously described cases

\begin{tabular}{|c|c|c|c|c|c|c|}
\hline & $\begin{array}{l}\text { Previously } \\
\text { published } \\
\text { cases } \\
\text { ( } 4 \text { cases) }^{1}\end{array}$ & $\begin{array}{l}\text { Patient 1, } \\
\text { family } 1\end{array}$ & $\begin{array}{l}\text { Patient 2, } \\
\text { family } 1\end{array}$ & $\begin{array}{l}\text { Patient 3, } \\
\text { family } 1\end{array}$ & $\begin{array}{l}\text { Patient 4, } \\
\text { family } 2\end{array}$ & $\begin{array}{l}\text { Patient } 5 \text {, } \\
\text { family } 2\end{array}$ \\
\hline Polyhydramnios & $Y($ all) & $\mathrm{Y}$ & $\mathrm{Y}$ & $\mathrm{Y}$ & Y & $\mathrm{Y}$ \\
\hline Hypotonia & Y (all) & $\mathrm{Y}$ & Y & Y & Y & $\mathrm{Y}$ \\
\hline Respiratory distress & $Y$ (all) & Y & Y & Y & Y & $\mathrm{Y}$ \\
\hline Facial diplegia & Y (all) & Y & Y & Y & Y & $\mathrm{Y}$ \\
\hline Absent swallow & $Y$ (all) & Y & $\mathrm{Y}$ & $\mathrm{Y}$ & Y & $\mathrm{Y}$ \\
\hline Low-set ears & unk (all) & $\mathrm{Y}$ & $\mathrm{Y}$ & $\mathrm{Y}$ & N & $\mathrm{N}$ \\
\hline Micrognathia & unk (all) & Y & Y & Y & Y & $\mathrm{Y}$ \\
\hline Cleft palate & unk (all) & Y & Y & $\mathrm{N}$ & $\mathrm{N}$ & $\mathrm{N}$ \\
\hline Epilepsy & unk (all) & $\mathrm{Y}$ & $\mathrm{Y}$ & $\mathrm{N}$ & Y & $N$ \\
\hline $\begin{array}{l}\text { Distal arthrogryposis } \\
\text { multiplex congenita }\end{array}$ & $Y$ (all) & $\mathrm{Y}$ & $\mathrm{Y}$ & $\mathrm{N}$ & $\mathrm{N}$ & $\mathrm{N}$ \\
\hline Age at death & $10-40 \mathrm{~d}$ & $\begin{array}{l}\text { Is now } \\
12 \text { y old }\end{array}$ & $\begin{array}{l}\text { Is now } \\
9 \text { y old }\end{array}$ & $\begin{array}{l}\text { Is now } \\
6 \text { mo old }\end{array}$ & $120 d$ & $1 d$ \\
\hline
\end{tabular}

Abbreviations: $\mathrm{N}=$ no; unk $=$ unkown; $\mathrm{Y}=$ yes.

The clinical findings of the 5 new CNTNAP1 patients lead to a better and extended characterization of the phenotype. All patients described so far presented with hypotonia, respiratory distress, facial diplegia, micrognathia, and absent swallowing. A history of polyhydramnios was present in all cases, probably as a result of the swallowing deficit. Including

Figure 4 Electron microscopy of sural nerves comparing patient 4 and with a healthy control
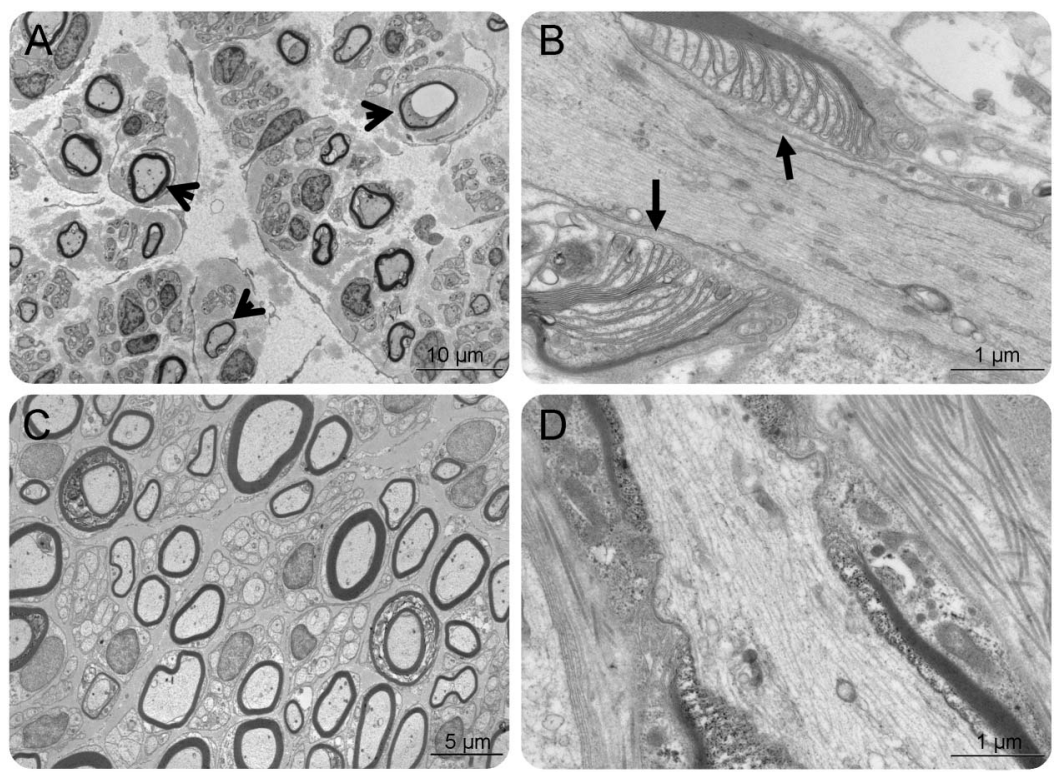

(A, B) Electron microscopy of sural nerve of patient 4. (A) Transverse section. Severe rarefaction of myelinated fibers; many have a too thin myelin sheath (arrows). (B) Longitudinal section. Abnormal widening of the node of Ranvier. The myelin loops are dissociated by the fingers of Schwann cell cytoplasm (arrows), which penetrate between the loops and the axon. (C, D) Age-matched control images. (C) Transverse section. Normal axonal density. (D) Longitudinal section. Normal node of Ranvier; the loops are closely attached to the axon our series, AMC was present in 6 of 9 patients with CNTNAP1 mutations described so far (table). This illustrates that AMC is not an obligate feature of CNTNAP1-related disease but most likely a secondary phenomenon due to hypotonia and, therefore, reduced fetal movements. Another feature that had so far not been related to CNTNAP1 is epilepsy. We found epilepsy in all cases that survived at least 120 days. As patients in the earlier series died only a few days after birth, it is tempting to speculate that these patients would likely have developed epilepsy, later on. The prolonged survival of more than 12 years in our patients stands in contrast to the short survival of the initially described patients with death occurring within 40 days of life. This is probably not explained by a milder phenotype, but by extensive medical care. The 12-year-old and 9-year-old patients underwent tracheostomy at the preterm intensive care unit and received nutrition via gastrostomy tube. Given the missense rather than truncating mutation, family 2 might be expected to present a milder phenotype due to a partially functioning protein. However, we did not observe a milder phenotype in family 2 compared to family 1 .

MRIs of our patients were taken at different ages and allow some cautious statements about the course of myelination. MRI of patient 4 was taken at 4 days of age. At this time, the expected first signs of myelination within the posterior limb of the inner capsule were missing in our patient; however, signs of atrophy were not present at that time point. MRI of patient 1 was taken at 5 years of age and showed a clear picture of hypomyelinating leukodystrophy. Even after 5 years, there were no myelin deposits. At this age, there was a marked reduction of cerebral, cerebellar, and pontine volume with pronounced lack of white matter. This suggests that the volume reduction is atrophy, at least to some extent secondary to hypomyelination. Furthermore, mega cisterna magna and thin corpus callosum were present in both patients (figure 3).

Findings in nerve biopsy of patient 4 are consistent with previous descriptions of CNTNAP1 cases. They share common features of hypomyelinating neuropathies with widening of the nodes of Ranvier and a great number of myelinated fibers with too thin myelin sheaths, but they also have very distinct features with lack of transverse bands at the paranodes and widened paranodal junctional gaps. Similar findings have been described in CASPR knockout mice and the shambling mouse harboring a CASPR missense mutation as well as other mouse models with paranodal junctional defects like contactin mutant mice ${ }^{14}$ or neurofascin-deficient mice. ${ }^{15}$ To the best of our knowledge, these distinct bioptic findings have been only described in the animal models mentioned above and not in humans.

Most of these findings are consistent with primary hypomyelination of the CNS and PNS, which can be 
explained by the well-established function of CASPR, i.e., the formation and preservation of paranodal junctions in the PNS and CNS. However, the massive neonatal symptomatology with microcephaly and early-onset epilepsy and the severe overall disease course are not common in hypomyelinating disorders but suggest a strong neuronal pathology. Other hypomyelinating leukodystrophies show primary developmental delay and usually some developmental progress during the first years of life. ${ }^{16}$ Furthermore, the severe supratentorial pronounced atrophy is another clue for additional neuronal/axonal pathology.

More recently, CASPR was shown to control the specification of neural progenitor cells in mice through notch signaling and is therefore regarded as a key regulator in the development of the cerebral cortex. ${ }^{17}$ Although MRI in neither patient displayed overt cortical maldevelopment, this dysfunction of CNTNAP1 is likely to interfere with cortical development and may contribute to early cerebral disease directly after birth when myelination is just beginning. Thus, both established functions of CASPR provide basic concepts of pathogenesis and explain the clinical findings. As shown in our case series, unique findings at neurologic examination as well as imaging and sural nerve biopsy can help to guide straightforward genetic diagnostics even in the absence of AMC.

\section{AUTHOR CONTRIBUTIONS}

$\mathrm{H}$. Hengel and A. Magee: drafting and editing of the manuscript, analysis and interpretation of data, and acquisition of data. M. Mahanjah, R. Sharkia, and J.-M. Vallat: acquisition, analysis and interpretation of data, and contributing to and revising the manuscript. M. Abu-Rashid and J. Mahamid: acquisition of data and contributing to the manuscript. M. Schulze: analysis and interpretation of data and contributing to the manuscript. I. Krägeloh-Mann: interpretation of MRI data and contributing to and revising the manuscript. R. Ouvrier, R. Schüle, and S. Züchner: contributing to and revising the manuscript. P. Bauer and L. Schöls: conceptualization of this study, study supervision, analysis and interpretation of data, revising the manuscript, and obtaining funding.

\section{STUDY FUNDING}

This work has been funded by the DFG trilateral project (reference number SCHO 754/5-2).

\section{DISCLOSURE}

P. Bauer received speaker honoraria from Actelion and is a paid consultant for Centogene AG. L. Schöls received speaker honoraria from Actelion. H. Hengel, A. Magee, M. Mahanjah, J.-M. Vallat, R. Ouvrier, M. Abu-Rashid, J. Mahamid, R. Schüle, M. Schulze, I. Krägeloh-Mann, S. Züchner, and R. Sharkia report no disclosures. Go to Neurology.org/ng for full disclosure forms.

Received October 19, 2016. Accepted in final form February 6, 2017.

\section{REFERENCES}

1. Laquerriere A, Maluenda J, Camus A, et al. Mutations in CNTNAP1 and ADCY6 are responsible for severe arthrogryposis multiplex congenita with axoglial defects. Hum Mol Genet 2014;23:2279-2289.

2. Bamshad M, Van Heest AE, Pleasure D. Arthrogryposis: a review and update. J Bone Joint Surg Am 2009;91(suppl 4):40-46.

3. Gordon A, Adamsky K, Vainshtein A, et al. Caspr and caspr2 are required for both radial and longitudinal organization of myelinated axons. J Neurosci 2014;34: 14820-14826.

4. Buttermore ED, Thaxton CL, Bhat MA. Organization and maintenance of molecular domains in myelinated axons. J Neurosci Res 2013;91:603-622.

5. Bhat MA, Rios JC, Lu Y, et al. Axon-glia interactions and the domain organization of myelinated axons requires neurexin IV/Caspr/Paranodin. Neuron 2001;30:369-383.

6. Sun XY, Takagishi Y, Okabe E, et al. A novel Caspr mutation causes the shambling mouse phenotype by disrupting axoglial interactions of myelinated nerves. J Neuropathol Exp Neurol 2009;68:1207-1218.

7. Gonzalez M, Falk MJ, Gai X, Postrel R, Schule R, Zuchner S. Innovative genomic collaboration using the GENESIS (GEM.app) platform. Hum Mutat 2015;36:950-956.

8. Li H, Durbin R. Fast and accurate long-read alignment with Burrows-Wheeler transform. Bioinformatics 2010; 26:589-595.

9. Vallat JM, Vital A, Magy L, Martin-Negrier ML, Vital C. An update on nerve biopsy. J Neuropathol Exp Neurol 2009;68:833-844.

10. Kumar P, Henikoff S, Ng PC. Predicting the effects of coding non-synonymous variants on protein function using the SIFT algorithm. Nat Protoc 2009;4:1073-1081.

11. Schwarz JM, Cooper DN, Schuelke M, Seelow D. MutationTaster2: mutation prediction for the deep-sequencing age. Nat Methods 2014;11:361-362.

12. Adzhubei IA, Schmidt S, Peshkin L, et al. A method and server for predicting damaging missense mutations. Nat Methods 2010;7:248-249.

13. Andres $\mathrm{KH}$. On the fine structure of special structures in myelinated nerve fibers of the rat cerebellum [in German]. Z Zellforsch Mikrosk Anat 1965;65:701-712.

14. Boyle ME, Berglund EO, Murai KK, Weber L, Peles E, Ranscht B. Contactin orchestrates assembly of the septatelike junctions at the paranode in myelinated peripheral nerve. Neuron 2001;30:385-397.

15. Sherman DL, Tait $S$, Melrose $S$, et al. Neurofascins are required to establish axonal domains for saltatory conduction. Neuron 2005;48:737-742.

16. Pouwels PJ, Vanderver A, Bernard G, et al. Hypomyelinating leukodystrophies: translational research progress and prospects. Ann Neurol 2014;76:5-19.

17. Wu ZQ, Li D, Huang Y, et al. Caspr controls the temporal specification of neural progenitor cells through notch signaling in the developing mouse cerebral cortex. Cereb Cortex Epub 2016 Jan 5. 


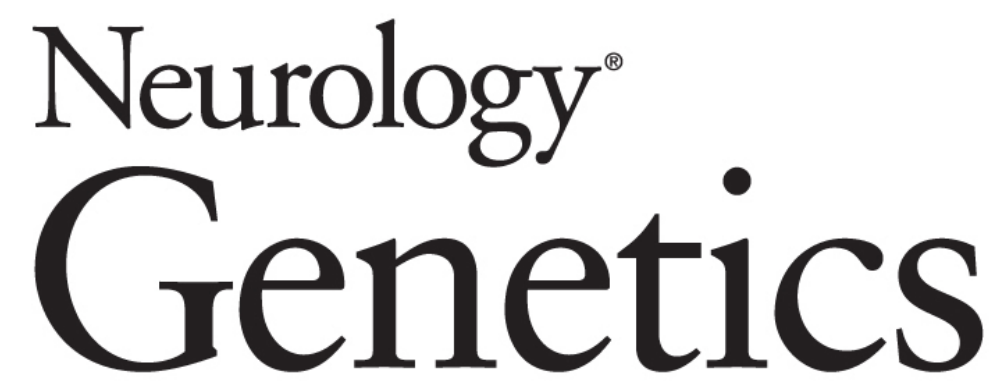

CNTNAP1 mutations cause CNS hypomyelination and neuropathy with or without
arthrogryposis Holger Hengel, Alex Magee, Muhammad Mahanjah, et al. Neurol Genet 2017;3;

DOI 10.1212/NXG.0000000000000144

This information is current as of March 22, 2017

Neurol Genet is an official journal of the American Academy of Neurology. Published since April 2015, it is an open-access, online-only, continuous publication journal. Copyright Copyright @ 2017 The Author(s). Published by Wolters Kluwer Health, Inc. on behalf of the American Academy of Neurology. All rights reserved. Online ISSN: 2376-7839.

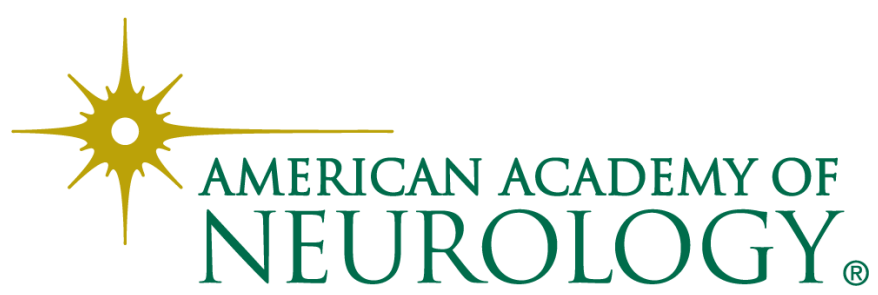




\section{Updated Information \& Services}

References

Citations

Subspecialty Collections

Permissions \& Licensing

Reprints including high resolution figures, can be found at: http://ng.neurology.org/content/3/2/e144.full.html

This article cites 16 articles, 2 of which you can access for free at: http://ng.neurology.org/content/3/2/e144.full.html\#\#ref-list-1

This article has been cited by 2 HighWire-hosted articles: http://ng.neurology.org/content/3/2/e144.full.html\#\#otherarticles

This article, along with others on similar topics, appears in the following collection(s):

\section{All Genetics}

http://ng.neurology.org//cgi/collection/all_genetics

Developmental disorders

http://ng.neurology.org//cgi/collection/developmental_disorders

Leukodystrophies

http://ng.neurology.org//cgi/collection/leukodystrophies

Peripheral neuropathy

http://ng.neurology.org//cgi/collection/peripheral_neuropathy

Information about reproducing this article in parts (figures,tables) or in its entirety can be found online at:

http://ng.neurology.org/misc/about.xhtml\#permissions

Information about ordering reprints can be found online:

http://ng.neurology.org/misc/addir.xhtml\#reprintsus

Neurol Genet is an official journal of the American Academy of Neurology. Published since April 2015, it is an open-access, online-only, continuous publication journal. Copyright Copyright @ 2017 The Author(s). Published by Wolters Kluwer Health, Inc. on behalf of the American Academy of Neurology. All rights reserved. Online ISSN: 2376-7839.

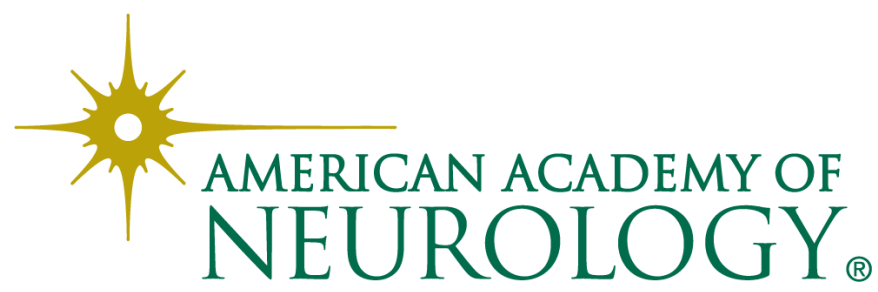

